\title{
EL CORTEJO EN LOS SAINETES Y TONADILLAS DEL SIGLO XVIII
}

Josefina PEREZ TEIJON

«Durante una gran parte del siglo XVIII algunos miembros de las clases acomodadas españolas entretenían su ocio con lo que podría describirse como relaciones extramatrimoniales, conocidas con el nombre de "cortejo". Los varones, denominados igualmente "cortejos", atendían a las damas y satisfacían sus caprichos de una manera parecida a los galanes del amor cortés» ${ }^{1}$. Así se expresaba en un artículo Philip Deacón en 1979, tomando como punto de partida las consideraciones que sobre este fenómeno hacía Nicolás Fernández de Moratín.

Carmen Martín Gaite ${ }^{2}$ ha dedicado un interesante ensayo a esta cuestión poniendo sobre todo de relieve los aspectos sociales y literarios tomando como principal fuente de inspiración los relatos de los viajeros que visitaron España durante la segunda la mitad del siglo XVIII. Y aunque para esta novelista y según sus propias palabras «no puedo por menos de sentirlos como personajes de ficción literaria, como inventados para ejemplificar la apatía y la resignación que desde los derrumbes de los sueños imperiales, venían caracterizando a los españoles», sin embargo, por los testimonios recogidos a través de algunos sai* netes y tonadillas, podemos pensar que no solamente se podían sentir como una ficción literaria, sino que respondían a una realidad más profunda y que tenía su asiento paradójicamente en las clases sociales que por tradición eran las más conservadoras y más profundas ${ }^{3}$. pág. 19-23.

1 Philip DEACON, "El cortejo y Nicolás Fernández de Moratín", B.B.M.P., n. $5,1979$.

* Carmen MARTIN GAITE, Usos amorosos del dieciocho en España, Lumen, Madrid, 1981.

- Véase mi libro: Contribución al estudio lingüístico del Siglo XVIII, Salamanca, 1985, 
De hecho, puede estar relacionado este fenómeno, con la mayor cultura que va adquiriendo la mujer y que se traduce en el mayor cultivo de las relaciones sociales, en el deseo de gozar de mayor libertad y en hacer gala de buen gusto.

La casada, dentro de las limitaciones que la sociedad le imponía, gozaba de mayor libertad que la soltera, porque la mujer soltera «no debe ser vista fuera de su casa, ni sentarse con ella un hombre, aunque las puertas estén abiertas; pero tan pronto como se casa puede ir donde le plazca y ser acompanada por un hombre varias horas al día ». De ahí que muchas mujeres prefieran estar casadas para gozar de esa libertad que parece negarse a las solteras.

Y como parece que la mujer no tomaba parte muy activa en la elección del marido, sobre todo entre las clases aristocráticas y burguesas, (los padres casaban a sus hijas, sin consultar sus sentimientos), esto podía dar lugar a que una vez casadas buscasen el esparcimiento al margen del hogar y de sus maridos. Los intereses de los padres se explicitan una y otra vez y siempre apuntan al mismo blanco: razones de tipo económico o deseos de ascender de clase social.

"No te canses (le dice Espejo a su mujer), que no quiero/ que se casen las muchachas/ hasta ver cómo se explica/ el Marqués; pues si lograra/casar a alguna con él/ a todas se titularan/ o casaran con barones, indianos o personazas/ de carácter, que a este modo/ se hacen soberbias las casas. (R.C., $369)^{5}$.

El mismo padre, y aunque esto no sea frecuente, en alguna ocasión, mostrará el deseo de que sus hijas tengan una formación de acuerdo con los nuevos tiempos, no importa que al final crea que esta educación no da los resultados que esperaba y se lamente de: "Ahora veo cuanto estraga/ el honor de las mujeres/ nuestra moderna crianza» (R.C., 230).

Pero se enorgullece en principio porque: «Ellas leen perfectamente/ en el castellano, y mascan/ el francés; ellas refieren/ de memoria todas cuantas/ comedias se han inventado;/ todas tocan la guitarra./ el salterio, el clavicordio/ [...] ellas juegan al volante/ y todo juego de cartas; ellas saben dar un aire/ extraordinario a las batas, /[...] En una conversación/ que se ofrezca, has de obser-

- Blanco Wite (1822), citado por René ANDIOC. Teatro y sociedad en el Madrid del sigle XVII. Cástalia, Madrid, 1988, pág. 422

Para los ejemplos tomados de Ramón de la Cruz he tenido en cuenta el Tomo 23 de la N.B.A.E. Colección ordenada por Emilio Cotarelo. Citaré solamente R.C. y la página. 
varlas/ que, aunque las hablen, no se atajan./ ¿Cuánto dieras tú por ver/ tu hija tan civilizada? * (R.C., pág. 370).

Son todas estas preocupaciones muy dieciochescas, pero sin un arraigo profundo, este mismo padre ante los resultados poco apetecibles o al menos no en consonancia con sus gustos, es fácil que vuelva a pensar como aquel otro personaje: « ¿Libros? ¡Bueno! A la mujer/ con saber hilar le basta,/ que ellas no han de manejar/ las plumas ni las espadas, (R.C., 165), o lo mismo que su hermano que le replica que sólo necesite a su hija para ser buena esposa: «ser cristiana, toda suerte de labores/ y gobernar una casa» (R.C., pág. 370). En casos aislados encontramos en las hijas casaderas, apoyadas por las madres también descontentas con su matrimonio, algún conato de rebeldía frente a la autoridad del padre. Ante el deseo de la madre de descasarse, la hija le replica al padre:

«Teresa.-Conque, padre;/ según esto,/ no necesito licencia/ para casarme.

Lucas.-¿̨Por qué?

Teresa.-Porque si usted me la niega,/ pondré yo pleito también/ para deshijarme.»

A Lucas no le queda otro remedio que reconocer que su autoridad se está resquebrajando.

«Lucas. $-Y$ hasta mi hija/ ni me teme ni respeta». (G.C., 250, II)

*Al hilo de lo que acabamos de exponer y de los ejemplos señalados, podemos entrever un poco cómo pudo y por qué arraigar la moda del cortejo, y nos parece que tiene mucho que ver con esa «civilización» de que hablaba el personaje de Ramón de la Cruz, que le abre a la mujer nuevas perspectivas y nuevas apetencias que se traducen en el deseo de mayor lujo y diversión frente a la sobriedad y el encogimiento; valores que en este momento considera anticuados y no en consonancia con la nueva mentalidad. Porque como dice Martín Gaite ala moda del cortejo, por muy pueril y estúpida que fuera, supone una importante revolución en las costumbres femeninas, significa la semilla de un primer cona-

- Rafael LAPESA, Historia de la lengua española, Madrid, 1980, en la pág. 430 dice:

"Ilustrar e iluminar, civilización y cultura, son las palabras clave en el siglo XVIII". Ver también: Werner KRAUS, "Sobre el destino español de la palabra francesa "civilization" en el siglo XVIII", Bull. Hisp., LXIX, 1967, 436-440: José Antonio MARAVALL, "La palabra "civilization" y su sentido en el sigto XVIII", Actus del V Cong. de Hispanistas, (1974), Bordeaux, 1977, 1, 79104.

Los ejemplos de González del Castillo están tomados de las Obras Completas editadas en tres tomos por la Real Academia Española, Madrid, 1914. Citaré solamente G.C. 
to explícito de malestar matrimonial, y dar lugar por primera vez a través de las polémicas que desencadenó, a una relativa toma de conciencia -aun cuando nuy minoritaria- con respecto a posibles reivindicaciones de la mujer en la sociedad» (Prólogo, XVII). Esta relación servía también para llenar el ocio de las mujeres, y las mujeres se sentían muy satisfechas, a juzgar por los testimonios recogidos, con esta moda y este nuevo estilo de vida.

Es cierto que muchas mujeres no soportan a sus maridos, y sin emhargo, se mostraban solícitas con los cortejos. El criado anuncia a la señora el deseu del amo de pasar a verla.

«Ciriaco (criado) a Doña Petra.-El amo espera licencia.

Da Petra.-Pase adelante. Este asno / ¿a qué vendrá? Cada día/ me fastidia más su trato.»

A la pregunta del marido: «Díme, niña mía: ¿cuántos/ te cortejan en el día?», contesta nuevamente con un exabrupto «Eso no te importa». (G.C., pág. 203, II). O ante la manifestación anıorosa de su marido: „Cómo te adoro, hija mía!, responde: Cállate o te tiro el plato/ a la cabeza. (G.C., 204, II).

Sin embargo no se muestra así con los tres cortejos. Al Conde, su cortejo, le inbla a que se ponga a su lado: «Señor Conde, aquí a mi lado». Fsta cercanía física se daba lugar a que la relación no se mirase con buenno ojos por parte de los moralistas y de la sociedard en general, y los esfuerzos por guardar las formas, que habían sido una preocupación en sus principios, se relajaban de acuerdo con la mayor libertad de las costumbres. Los maridos mostraban una ciertá hostilidad a estas relaciones: «Ciriaco,-Y al scñor don Alejandro/ le está dando finecitas». El marido contesta: «Finezas, y yo chupando/ los huesos que él ha roído! » (G.C., 211).

En lus sainetes, si bien se debe tener en cuenta lá exageración propia de toda sátira donde, evidentemente, se trata de ridiculizar y abultar una situación, el marido representaba la exclavitud conyugal, lo convencional, la monotonía, el aburrimiento, etc. El cortejo, por su parte, era símbolo de la libertad, de la ocupación alegre y divertida que muchas mujeres necesitaban para llenar. el tiempo libre: «Isadora.-Pues don Pedrito, conmigo/ tendréis muy poco trabajo/ [...] y sólo la calle Ancha' entre once y doce es cl campo/ donde pucde una mujer/ soltar las riendas el garbo,» (G.C., 267); y debían sentirse muy decepcionadas cuando no lograban una de estas relaciones extramatrimoniales que para algunas mujeres casi eran vitales; «Paca.-Pues hija,/ cada una siga su empeño, que yo no puedo vivis/ sin mi cacho de cortejo» (R.C., 361). 
Significaba, en suma, la imnovación, la libertad, el deseo de estar a la moda, el buen gusto. Bien se lo dice el Marqués, cortejo, a una dama que quiere abandonar a los cortejos y volver con su marido: «Esta noche borremos/ su nombre del diccionario/ del buen gusto».

Según Luis Joseph Velázquez, autor de un escrito satírico sobre el tema y citado por Philip Deacon, el beneficio del cortejo para la sociedad consistía en traer entretenida a la gente ociosa [...] y para las mujeres era la constante compañía de los hombres. Las mujeres se sentían halagadas con estos acompañantes que tenían como una de sus misiones estar pendientes de cualquier contratiempo de las damas y derrochar siempre amabilidad y buen trato. En principio las relaciones eran supuestamente inocentes y se basan sobre todo en meras conversaciones. Pero esos visos de inocencia con el tiempo dejaron paso a ciertas sospechas de relaciones menos blancas y en general eran vistas por la mayor parte de la sociedad como un peligro para la estabilidad matrimonial. Se podría decir que se daba en ellas la presunción de inocencia por deferencia hacia la mujer.

* Los maridos se dividían en dos netos sectores, el decir de Carmen Martín Gaite, "los que admitían la moda del cortejo, más o menos a regañadientes, y los que apoyados por la opinión mayoritaria de los moralistas y predicadores, no pasaban por ella. La primera actitud se consideraba de buen tono, la segunda anticuada». (Intr. XV).

Es cierto, también, que estas visitas planteaban con frecuencia un problema, que veía amenazada la intimidad del hogar", y muchos de los textos contemporáneos tocan esta cuestión. «Yo/ con estos señores hablo, con estos hombres ociosos/ que emplean sus torpes años/ en fomentax la flaqueza/ del bello sexo, turbando/ la quietud de las familias, / rompiendo los dulces lazos/ de muchos esposos, / que fueran afortunados/ sin sus asechanzas». (G.C., 219, II).

La Tonadilla Escénica ${ }^{10}$ señala con dos ejemplos, no exentos de fina ironía, esa aceptación o rechazo del cortejo por parte del marido y la reacción consiguiente de la mujer y su acompañante en cada caso. De cualquier forma, el marido era consciente de cuánto engaño y ridículo conllevaba aquella situación.

En este primer ejemplo se expresa el susto de la dama y su cortejo ante la inesperada llegada del marido.

a Philip DEACON, art. cit., pág. 90.

Ibid., pág. 91.

10 José SUBIRA, La Tonadilla Escénica, T. III, Madrid, 1930. Citaré T.E. 
«Cuando está alguna dama/ con su cortejo/ (cabal que así sucede/ lo mismo que lo cuento)/ a solas en sus glorias, / son sus contentos./ Y en sintiendo algún ruido/ se asustan con miedo./ Ella le dice al majo:/ "Don Juan, ¿qué será esto?/ ¡Ah! Mi marido viene, ¡Pobre de mi! ¿Qué hacemos?/ ¡Ay, don Juan de mi alma/ Yo me muero, me muero"/ El majo se acobarda, y asustado y perplejo,/ anda dando mil vueltas/ dentro del aposento.»

En el ejemplo siguiente la reacción es distinta, la dama no teme la llegada del marido que conoce perfectamente esta relación y la admite.

*Otros cortejos/ aunque ven al marido/ se están muy quedos./ No hacen altos ruidos/ y las damas, sin miedo, / les dicen que no teman, / que allí no están violentos./ "Si mi marido viene,/ bien sabe lo que hacemos./ De susto no le coge./ El no repara en eso./ Mi marido es buen hombre./ Por eso yo le quiero./ Y bien sabe que estamos/ dentro del aposento.»

Es decir, que la bondad (entrecomillada) del marido, estaba en función de su aceptación, pero las reacciones ante esta realidad, que aparenternente creaba tantos conflictos, apuntaban sobre todo hacia su rechazo.

«Fste es gusto y después/ todos lienen su infiemo./ Madamas mías, cuen. ta/ con este cuento,/ que el cortejo ucasiona/ tales extremos.» (T.F.., pág. 38, 'I'.III).

Incluso el marido que lo acepta no deja de amonestar a su mujer previniéndola de los males que la compañia del cortejo acarrea: "esos mono de cortejos/ ocupan siempre tu estrado,/ hieren tu reputación/ y hacen que yo sca el blamen/ de la sátrira del pueblo.» (C.C., 220, II).

*Obligaciones de los cortejos.

Es curiosa la pregunta que le hace un cortejo substituto a la dama:

«Pedro.-Pues es fuerza que sepamos/ que servirins quiere usted:/ ¿los vistos a los privados?»

Cabe señalar que sus ocupaciones eran muchas y diversas, unas en casa y otras fuera de casa, pero intentar sumergirnos en el cuestionamiento de la bondad o malicia de esas actividades, obviamente carece de interés, era la ambigüedad de sus funciones y lá riqueza de matices, uno de sus mayores atractivos, y lo que interesa destacar, en suma, es que para la mujer representaban la liberación de una situación poco acorde con los nuevos tiempos.

"Con unas sólo me obligo/ a llevarlas al teatro,/ al paseo, a la visita:/ y con 
otras me contrato,/ para el tocador, la mesa,/ la tertulia y el estrado.» (G.C., pág. 267, I).

Estas actividades podían completarse con otra más delicada, la de ser en ocasiones el confidente de la dama, la persona a la que revelaba sus cuitas, lo que induce a pensar que ésta debía ser muy prudente a la hora de elegir cortejo, porque su honor también dependía a veces de la categoría y discreción de ellos. Paula da a sus amigas una serie de consejos que les serán útiles a la hora de admitir a un cortejo: «tan solo/ que miréis con juicio os ruego/ que, sea por vanidad,/ por costumbre o pasatiempo,/ veáis a quien admitís/ a vuestro lado, temiendo/ la lengua del admitido/ y del desairado el ceño, / los ojos de las vecinas/ y el escándalo del pueblo» (R.C., 361); así que las más prudentes no eligen al azar sino con sumo cuidado entre varios pretendientes porque como vemos en esta elección exponían mucho.

Este modo de elegir cortejo tiene muy poco que ver con el testimonio del epistolario del italiano Giuseppe Baretti (en la Carta LVIII fechada en Madrid el 11 de octubre de 1760 habla sobre su ceremonial y reglamento $)^{11}$. En ella cuenta que el último día del año se reúnen los amigos por la tarde para sortear los años. La persona más joven de la reunión saca el nombre del caballero con una mano y el de la dama con otra. Estas dos personas serán años durante doce meses. Así el año queda, en cierta manera, incorporado a la familia y asistirá a la dama a cualquier hora del día. También habla de los estrechos, que se diferenciaban de los años en que eran elegidos la víspera de Reyes.

Segín este testimonio no hay elección, era el azar el que unía a una dama con su año, y éste además, pertenecía a su círculo de amistades.

Los sainetes y tonadillas consultados no reflejan esta situación, por el contrario en estas obras, las damas eligen a sus cortejos (que casi nunca pertenece a su círculo de amigos), entre los nobles, casi siempre arruinados y desocupados (téngase en cuenta el desprestigio en que en este momento ha caído la nobleza); otras veces son petimetres, o señoritos de tres al cuarto. La categoría del cortejo estaba también en función de la categoria de la dama, y a más categoría más prudencia y rigor había que mostrar para elegir al candidato o candidatos, porque a veces una dama disfrutaba de la compañía de varios cortejos.

«Paula.-¡Elegir! ¿pues qué? ¿esta es cosa/ que se hace sin un perfecto/ examen? Un hombre a quien/ he de confiar mi corazón./ Aquél que ha de parecer/

"Tbid., pág. 87. 
a mi lado en los paseos, / en comedias y visitas, [...]/ Para conservar mi homor./ no he de saber si es modesto?/ Para que pueda sufrirle/ mi familia, jsi es atento./ afable y no entrometido?/ Y, por remate del cuento, jsi es hombre de tan prudente/ conducta, si es tan discrelo/ y puro que janás jueda/tener mi marido celos?" (R.C., 358). Como puede comprobarse, una vez elegido, se incorporaba irmediatamente a su círculo familiar y la entrada y salida en la casa no dobía dar a ninguna sospecha, era un servidor más, y por lo tanto la información que necesitaba para elegir cortejo, debía ser a lo menos la misma que pediría a la hora de contratar a un criado:

"Paula.-Pues dime:/ ¿No debo hacer a lo menos, la que un cortejo recihe, / las diligencias que haccmos/ e informes con que un criado/ recibimos? *

Pero observemos ahora la contestación que le da la otra:

«Paca,-No por cierto;/ porque también despedimos/ más fácilmente un cortejo/ que un lacayo». (R.C., pág. 358). Bien se nota entonces que sus servicios no tenían una duración determinada y que se podía prescindir de ellos en cualquier momento.

Otra dama se resistía a contratar los servicios de los cortejos, pero el buen gusto, el qué dirán y una seric de condicionamientos sociales, hacen que por fin acceda, aunque, en su cabal prudencia: "quiere escoger entre cicnto/ el de más méritos, más galán, valiente y discreto.» (R.C., 357). Nótese que la discreción es una de las cualidades en que hacen nás hincapié las damas, esto nos obliga a pensar que la mujer adoptaba un aire de seriedad en sus relaciones extramatrimoniales que cerraba la entrada a la discusión, teniendo en cuenta que estas damas pertenecian a las clases más poderosas y con mayor prestigio, y que 1 o querían perder los privilegios que su condición de casadas les otorgaba.

*En cuanto a la duración de los cortejos no encontramos testimonios claros que indiquen el tiempo que permanecían al servicio de la dama. Fs fácil que esta duración estuviese supeditada a sus caprichos y necesidades, lo que sí parcce cierto es que un mismo cortejo servía a distintas damas y que además, en ocasiones necesitaba los servicios de los llamados cortejos sustitutos ${ }^{12}$, que las acompañaban en ausencia de los propietarios.

"José.-Pues, Periquito; mi encargo/ se reduce a que esta noche/ acompanes a un sarao/ a mi doña $A$ na.»

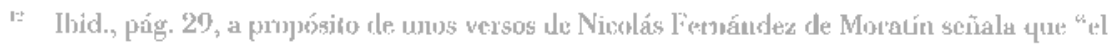
cambio de rorrejo acompaña el cambio del año". 
Mucho trabajo debían de tener esos cortejos sustitutivos, porque en más de una ocasión se quejan de que los propietarios abusan de ellos y les encomiendan más funciones de las que pueden desarrollar.

«No puedo; (contesta Periquito)/ eso ya es mucho trabajo/ ¿Qué pretenden los cortejos?/ ¿No consuelo, no acompaño/ sus damas en las ausencias y enfermedades? (G.C., 262, I). Y aún llega a más. Pediré que me jubilen/ si aprieta más el trabajo:/ y si no que me señalen/ un compañero.» (G.C., 267, I).

El tiempo libre que les queda a los cortejos para otras actividades que no fueran acompañar a las damas casadas, era escaso, las solteras, debido a esta situación, se veían totalmente marginadas y solas, por eso aceptar a un marido, aunque éste no fuera de su agrado, debía ser para ellas una especie de liberación. "Lo nuevo del fenómeno residía en que se habían complicado los motivos de esta impotencia de las solteras por casarse, y que el aumento de alicientes que adquría el inatrimonio a sus ojos estaba en razón inversa con los que tenía para los hombres ${ }^{18}$. Por una parte los cortejos se quejan con mucha frecuencia de las rígidas exigencias del código del cortejo que no les dejaba ni un momento libre, y por otra parte, los maridos támbién sufren las vejaciones y malos tratos que reciben de sus mujeres y cortejos apoyados en las Ordenanzas de este código.

«Pedro (cortejo),-No es posible:/ y si no mira el estado/ de los cortejos del día./ Doscientos hay embarcados; quinientos están enfermos; trescientos andan viajando; / ciento y ochenta suspensos, / y diez que han abandonado/ sus puestos cobardemente.» (G.C., 263, I).

Policarpo es uno de los maridos que sufre casi estoicamente esas ordenanzas, y aunque el texto es amplio. merece la pena reproducirlo en parte.

Alejandro (cortejo) lee: «Libro segundo,/ capítulo veinticuatro:/ Cuando estuvieren dos, tres/ o más cotejos sitiando/ a la dama, si el marido/ está presente al asalto./ cuidará de los bagajes/ a gran distancia del campo.»

$[\ldots]$

«Tratado/ de los delitos y penas:/ El marido que al mandato/ de su esposa se resista,/ queriendo escuchar, osado,/ los secretos del cortejo,/ pagará su desacato/ con tres dás de destierro/ de la mesa y del estrado.» [...]

13 Martín GAITE, op s cit, pág. 133. 
Polic. (marido).-Pues, señor, zqué Ordenanzas/ son esas de dos mil diablos?.

Conde._Qué Ordenanzas? las tareas/ de cuarenta curratacos/ eruditos, que consagran/sus ratos desocupados/o bien de la Humanidad. »

Polic,-Muy bien; pero ¿qué pecado/ he cometido?

Marqués.-jFriolera!/ querer saber los arcanos/ del cortejo.

Polic,-Mire usted;/ yo en algún modo/ me conformaría, cuando/ corriesen algunos días/ los cortejos con el gasto.» (G.C., 210, II).

Aparte de la exageración que puede haber en este texto, no obstante la crítica que en él aparece va siempre dirigida hacia la debilidad que el marido muestra en esta y en otras muchas ocasiones y que da lugar a situaciones tremendamente ridículas: corre con los gastos, admite vejaciones de su esposa y de los cortejos y la lamentación es la úmica solución que le queda. Se trata de abultar una situación, pero la situación realmente que había incubado en las clases altas de la sociedad y que el pueblo en más de una ocasión trató de imitar, o al menos le sirvió de blanco de sus sátiras y a muchos sainetistas de motivo de inspiración.

Podemos decir que el interés del cortejo radicaba en esa indeterminación de funciones que nunca quedó claramente despejada, en la complejidad del fenómeno, en la ambigizedad de su conducta o mejor de la condueta de las damas en sus relaciones con ellos. Su continua descalificación a medida que va avanzando el siglo, amenaza con su supervivencia, pero quedará siempre como testimonio de esa apertura de costumbres afanosamente buscada y conquistada por la mujer en sus aspectos más conflictivos y que sistemáticamente le había sido negada, a tenor de argumentos en pro de la moral y las buenas costumbres.

Toda esta indefinición del cortejo queda magníficamente reflejada en estos versos de Ramón de la Cruz:

Eusebio.-Pues ¿qué es el cortejo? ¿es más

que una aprendión o un misterio

de las gentes enemigas

del político comercio?

Espejo.-_El cortejo aprensión! Id

y preguntárselo a ellos,

y os dirán si es aprensión:

pasar la vida sujetos, 
aspirar a ver contenta

una mujer, sufrir celos,

no proponer esperanzas,

ni anhelar jamás el premio

$[\ldots]$

$y$, en fin, cuando haya logrado

la perfección del obsequio,

irse muy enhoramala

y quedarse padeciendo. (R.C., 357).

El salmantino Torres Villarroel, no alude en sus sainetes a esta figura tan típicamente diocechesca, pero sí a la del estudiante poco amigo de los libros y más atento al Arte de Amar de Ovidio.

«Los más que en Salamanca/ son escolares,/ sólo estudian de Ovidio/ el Arte Amandi." (T.V., 43). 